\title{
A PHENOMENOLOGICAL ONTOLOGY FOR PHYSICS Merleau-Ponty and QBism
}

\author{
Michel Bitbol \\ Archives Husserl, CNRS/ENS, 45, rue d'Ulm, 75005 Paris, France
}

in: H. Wiltsche \& P. Berghofer, (eds.), Phenomenological approaches to physics, Springer, 2020

\section{Foreword}

Let's imagine that, despite the lack of any all-encompassing picture, an abstract mathematical structure guides our (technological) activities more efficiently than ever, possibly assisted by a set of clumsy, incomplete, ancillary pictures. In this new situation, the usual hierarchy of knowledge would be put upside down. Unlike the standard order of priorities, situationcentered practical knowledge would be given precedence over theoretical knowledge associated with elaborate unified representations; in the same way as, in Husserl's Crisis of the European Science, the life-world is given precedence over theoretical "substructions". Here, instead of construing representation as an accomplished phase of knowledge beyond the primitive embodied adaptation to a changing pattern of phenomena, one would see representation as an optional instrument that is sometimes used in highly advanced forms of embodied fitness. As for mathematical formalisms, they would no longer be taken for a structural image of the actual world, but rather understood as a systematic inventory of our most precise possibilities of bodily action in response to a varying phenomenal landscape (along with Jean Piaget's genetic psychology or Andrew Pickering's neo-pragmatism). The Platonician dream of knowing natural forms would be dispelled by the realization that the theories of mathematical physics are variants of a formalized know-how.

\section{Quantum physics as formalized know-how: what are the resistances?}

In the eyes of any lucid and unprejudiced thinker, it is obvious that quantum physics is a perfect instantiation of this kind of post-classical conception of knowledge. In quantum physics, it has soon been suspected (especially by Niels Bohr) that a fully coherent all-encompassing representation might well be out of reach. At most, one can provide a mathematical scheme that has the mental function of a "representation" without pretending to be literally a

1 This work was supported by the Agence Nationale pour la Recherche (ANR-16CE91-0005-01). 
representation of the world (Schrödinger 1951, p. 40; Bitbol 1996 p. 29). The reason of this apparent limitation of quantum physics is clear to almost anyone. It is the contextuality of micro-properties, the fact that microproperties cannot be disentangled from the material and bodily context of their manifestation. Due to contextuality, no independent domain of properties and entities can properly be defined, let alone represented. But physicists soon realized that the lack of a unified representation and the unbreachable contextuality of properties were absolutely no hindrance to the efficiency of the mathematical scheme of the theory. They then used it with amazing success, as a universal chart of microphysical know-how.

It is thus prima facie surprising that, for nearly one century, there has been continuous struggle against those unexpected but strong conclusions. Many scientists felt that lacking a unified and consistent narrative about the world is tantamount to falling into non-sense. And they desperately attempted to overcome what they saw as a failure.

Very few researchers tried the opposite strategy that consists in pushing Bohr's approach to its ultimate consequences, thus making sense of the collapse of representations, and looking for a new process of sense-making below the level of representations; say at the level of the phenomenology of perception and action. Very few of them decided to explore the surface of micro-phenomena, and to make sense of their being limited to this so-called surface, rather than trying desperately to tell a tale about the elusive depths hidden behind phenomena. For some time, I had the feeling that this stubborn attitude, this resistance against the radical epistemological lesson of quantum physics, is a constitutive feature of our Western ethos.

Why, if not because of a deeply entrenched cultural obstacle, would a new conception of knowledge that makes sense of our most advanced physical theory not be more widely accepted? Why does it so often find itself opposed by the indignant reactions of certain physicists who reproach it with "betraying the ideal of science" (Stengers 1997). Why do some mathematicians accuse quantum theory of being unacceptable or even "scandalous" (Thom 1993)? Why, even when indignation is absent, does the exposition of the minimalist conception of quantum theory give rise to a resigned silence which manifestly expresses a profound disappointment?

This might be due to the fact we are dealing with a breach of several tacit contracts of our civilization. One of these is a fairly recent contract, signed at the end of the sixteenth century, between the desire for a metaphysical breakthrough that motivates scholars, and the craftsmen's need for technological improvement (Scheler 1993). There is also a much older contract, dating back to ancient Greece, which has made it an obligation to look for a principle of understanding superficial appearances in the inmost depths of things (Schrödinger 1954), and to seek there the changeless source of any change. 
If scientific progress does not help our gaze to penetrate into the very heart of material bodies, and to definitively guarantee technological effectiveness by laying bare their secret, what is the point of it? If the progress of knowledge amounts merely to a kaleidoscopic deployment of the phenomenal skin of things, instead of opening up an insight into their very flesh and marrow, does it not seem vain? One may recall that the entities which, in the history of science, were given the title of "realities behind appearances", have turned out to be: (1) other appearances (or phenomena) revealed by a new approach or (2) mathematical idealities which express some invariants of the said phenomena. However, this simple reminder is not enough. The "dream of reason" pursues its course; this same dream that Kant upheld at the beginning of his quest, before discarding it in his critical philosophy: the dream of grasping by thought a "representation of things as they are" (Kant [1770] 2004).

\section{The new understanding of quantum mechanics}

But several recent debates and ideas in the philosophy of quantum mechanics suggest, to my delight, that things are now changing at a fast pace. Several new philosophical readings of quantum physics all point in the same direction, the direction of full recognition of the fact that the quantum revolution is above all a revolution in our conception of knowledge. Apart from Asher Peres' remarkable "no-interpretation" of quantum theories, which radicalizes the so-called Copenhagen interpretation, the forerunner of this new trend was probably the information-theoretic interpretation of Anton Zeilinger and his school. According to this interpretation, the information made available by experiments exhausts "reality"; and the formalism of quantum theories is derivable (to a certain extent) from a principle of limitation of the information that can be extracted from each system. As for this principle of limitation, it is an operational formulation of the widely acknowledged contextuality of microproperties. From this kind of derivation, or "reconstruction" (Grinbaum, 2007), it becomes clear that quantum theories are not to be understood as an indirect representation of some reality beyond the phenomenal level of experimental information, but as a direct expression of some in-principle bounds of the availability of this information.

Recent developments in the use of quantum theories can be seen as an implicit confirmation of the relevance of an information-theoretic reading. One case is especially striking: it is a recent generalization of quantum theory that applies to several domains of the human sciences (Bruza et al. 2009a, Bitbol 2009) such as decision theory, semantics, and the psychology of perception. This application of quantum theory to the human sciences shows that no matter who or what responds (human beings or things), the probabilistic structure that is to be used to anticipate the responses is roughly similar. A set of human beings making choices that depend on the options which are presented to them, and on the order of the decisions to be taken, behaves to a certain extent like a set of electrons on which one evaluates several incompatible observables 
(Zwirn 2009). In particular, a set of speakers who must make a decision concerning the meaning of a polysemic word, according to the propositional contexts, violate the Bell inequalities (Bell 1987), just as a set of microparticles do (Bruza et al. 2009a, b). There is nothing shocking about the fact that it should be so. For this implies strictly nothing about some alleged similarity between electrons and humans at the level of their profound being. There is only an isomorphism between the possibilities of epistemological access to electrons and to humans: a rough isomorphism of their phenomenal reactions to being solicited, and of their informational dispositions.

True, the amount of contextuality is not necessarily identical in both situations, namely in physics and in the human sciences (Aerts \& Sozzo, 2014). A quantitative assessment of their discrepancy with respect to classical, noncontextual, predictions, can even be given by comparing their respective deviations from the gold standard of the original Bell's inequalities. For standard quantum mechanics, the maximal value of this deviation is given by the "Tsirelson bound" (Tsirelson, 1987).

Irrespective of their quantitative differences, however, the universal applicability of quantum-like theories to any domain in which the replies to experimental solicitations depend on their order, strongly suggests that these theories are mostly that: a general procedure for anticipating probabilistically the replies to context-dependent experimental solicitations. They are likely to offer little help (if any) in the quest of a faithful representation of some independent reality out there, behind phenomena.

There is also a well-known philosopher of quantum mechanics, who previously held a subtle realist interpretation of this theory, and who now considers that acknowledging the impossibility of a realist interpretation is a condition for the understanding of this theory. This is Richard Healey. His analysis is exceptionally lucid, even though he sometimes balks at its ultimate consequences (possibly a remnant of his former realist self). According to Healey $(2017$, p. X), "The main barrier to understanding quantum mechanics is not our inability to imagine the world it describes, but the presumption that it be understood as describing the world". In other terms, the feeling that quantum mechanics is still mysterious one century after its first formulation, might well be due to our refusal to accept its non-representational status. Healey thus classifies the many approaches of quantum physics into two (unequal) subsets: those held by the interpreters (the majority by far) and those held by the pragmatists (a minority). Both approaches agree that there is something exceptional in quantum physics, but disagree about the nature of this exception. Interpreters try to figure out a picture of the universe or multiverse that may resemble Alice's wonderland, but that fits more or less squarely with the formalism of quantum mechanics. Interpreters literally look for a proper "interpretation" of quantum mechanics. Pragmatists, instead, examine the use of the formalism, and they conclude that what is truly radical in quantum physics is that there is nothing deeper in it than the rules of its use; 
nothing like an account of the "universe". Interpreters project the exceptional features of quantum physics onto their objects of thought, whereas pragmatists withdraw from projections and identify the source of this exceptionality in a revelation of the true workings of knowledge that was hidden by classical science. Interpreters are focused onto possible intentional objects, whereas pragmatists come back reflectively towards the condition of possibility of any knowledge of objects. Interpreters adopt a naturalist attitude, whereas pragmatists sketch a phenomenological attitude. To recapitulate, according to pragmatists, quantum physics needs no interpretation, but rather a clear recognition of the reason why there can be none. This is a motto that will be developed later in connection with the quest for an unconventional ontology that fits non-representational readings of quantum theories.

\section{Suspending the interpretations of quantum mechanics: a phenomenological epochè for physics}

What might be a non-interpretation of central symbols of quantum mechanics? The standard language of quantum physicists calls "states" certain vectors of a Hilbert space; it then presupposes that these symbols express the intrinsic state of real systems. Instead, in the pragmatist, non-interpretational approach to quantum physics, these vectors have no value as predicates of systems, but only a function for those who try to explore these so-called "systems". The function of these vectors is to provide an informational bridge between the preparation and the outcome of experiments, or more generally (to borrow Healey's terms) between the "backing condition and the advice condition" of each physical situation. To sum up, the said vectors of a Hilbert space are no absolute characteristics of systems, but rather predictive tools relative to each agent-situation.

The latter deflationary way of featuring the so-called "state-vectors", that no longer deserve to be called "states", has been pushed even further by another approach to quantum physics (Fuchs et al. 2014): QBism, that can be read "Quantum Bayesianism" or "Quantum Bettabilitarianism". QBism in its original form as quantum Bayesianism asserts that "state" vectors are a special variety of Bayesian probabilistic valuations, and that probabilistic valuations are logical constructs rather than physical realities. Here, "state" vectors and probabilistic valuations are not statements about what is the case, but statements about what each agent can reasonably expect to be the case. Ultimately, they are just expressions of what one subjectively expects to be the case; they express each subjective agent's willingness to place bets on such and such outcome. Hence the alternative expression for QBism: "Quantum Bettabilitarianism".

Several features of these non-interpretational, non-committal approaches of quantum physics strongly evoke the phenomenological attitude.

The first one is a deliberately first-person approach (be it first-person singular or first-person plural). The project of both phenomenology and non- 
interpretational approaches to quantum mechanics is to reconstruct a new, selfconscious, type of objective knowledge, starting everything afresh from the first-person standpoint of knowers and agents.

The second common feature is the act of suspending judgment about a presumably external domain of objects, and the subsequent redirection of attention towards the mental or practical activity of constitution of these objects. In phenomenology, the suspension of judgment is called the epochè (after the Greek skeptics), and the redirection of attention towards the mental acts by which one comes to believe in the existence of perceived objects is called the phenomenological reduction. In QBism, and in Healey's pragmatic approach as well, the suspension of judgment is also clear, since one here considers that no symbol of quantum mechanics refers to objects or denotes predicates of objects. The reflective redirection of attention is just as obvious, since now attention is redirected towards the epistemic function and the practical use of the symbols of quantum mechanics. In QBism, these symbols only represent the probabilistic weights that an agent can use to bet on the outcomes of experiments. And in Healey's pragmatic approach, these symbols are relativized to various agent-situations, and their role is to be guides for agents, by giving rigorous prescriptions about how to set their beliefs.

The third common feature, that is specifically developed by Laura de la Tremblaye (2020), is the very structure of quantum knowledge as understood by QBism and pragmatism. This structure combines a bundle of expectations, expressed by a state vector and an observable, with some rules to take concrete empirical outcomes into account for redefining the expectations (this is the famous "projection postulate"). Such a combination comes remarkably close to Husserl's phenomenological theory of perception, with its horizons of expectations that can be fulfilled or disappointed by "intuitive contents" made of sensory hylè .

\section{Reconstituting ontology after the epochè}

But the central question I would like to raise goes beyond the level of structure to address the issue of ontology. Even if one adopts Richard Healey's "pragmatist" approach, that is deliberately non-interpretational, there may be a way towards a sort of meta-interpretation of the situation that makes interpretational views so clumsy and so fraught with paradoxes. Even if one considers that quantum physics does not provide us with the smallest hint of a representation of the world, another question can still be asked: what should the world be like in order to display such resistance to being represented as an object of thought? Answering this question would be tantamount to formulating a new kind of ontology, a non-object-based ontology, an ontology of what cannot be represented as an object external to the representation itself. One may think of several candidates to the title of a truly alternative ontology.

One of the most venerable is perhaps that of Schopenhauer. The very title of Schopenhauer's masterpiece evokes such an alternative ontology: The World 
as Will and Representation. Here, the world is not something which must be represented. To a certain extent, it coincides with the lived representation itself; and yet it is more than this representation, since what representation pictorially expresses is the outcome of an obscure impulse that moves everything, and takes in us the form of desire and action: the Will. According to this conception, we are not facing the world, as our representation falsely suggests, but we coincide with the world qua dynamical process and inner impulse; and the representation is just a projection of the oriented power of this dynamical process. In Schopenhauer's philosophy, Kant's "thing in itself" assumes a non-conventional meaning. Schopenhauer's "thing in itself" is not external to the knower but consubstantial with her. Then, the reason why, according to Schopenhauer (and possibly Kant), the "thing in itself" cannot become an object of knowledge, is precisely its lack of distance with respect to us. We tend to be blind to what is too close to our eyes. This is a first sketch of the kind of ontology that would fit a branch of physics such as quantum mechanics, in which the possibilities of separating the known object from the act of knowing are scarce (a feature that is well-known since Kochen \& Specker's theorem as "contextuality").

Now, other ontologies that have this special quality are phenomenological ontologies. I will not say much about Husserl's methodologically idealist ontology. Let me just remind you that Husserl took the Cartesian doubt as a starting point. Then, he transformed this doubt into a universal epochè, or suspension of judgment about any claim of existence of wordly objects. And he retreated to the only domain of "apodictic certainty" of which any claim of inexistence would be performatively contradictory, namely the domain of "pure conscious life" (Husserl 1960, p. 21). By contrast, "all positions taken towards the already-given objective world", said Husserl, must be "deprived of acceptance", or "inhibited" (Husserl 1960, p. 20). The worlds of science and everyday life are then downgraded to the rank of mere phenomena that "claim being" (Husserl 1960, p. 18), whereas "pure conscious life" is raised to the rank of "the whole of absolute being" (Husserl 1982, §51). As I have mentioned above, this complete reversal of the ontological hierarchy is usually dismissed as a variety of idealism. Husserl somehow endorsed such a characterization of his philosophy as "idealist", but he gave the latter word a performative rather than doctrinal acceptation. His "... idealism is not a metaphysical substruction ... but the only possible and absolute truth of an ego ... recollecting itself on its own doing and its own ability to give meaning" (Husserl 2007, p. 48). Dogmatic idealism can then be seen as a reification of this performative idealism. It arises when one turns the phenomenological activity that consists of "recollecting" one's own conscious life, and identifying the lived roots of one's "natural" beliefs, into a thing (res cogitans).

Would such a conservative ontology be an acceptable ontology for physics? I am not completely averse to it. After all, what else do we have in order to support further ontological claims than this pure conscious experience which, 
according to Husserl, is "the whole of absolute being"? Positions such as Bohr's, who sometimes declared that the primary task of physics is to introduce some order within human experience, and Chris Fuchs', whose slogan is "experience first", should be considered as reasonable options, rather than being automatically dismissed as "solipsistic".

Yet, there is something specific to physics that is not easily encompassed within a methodological idealist ontology such as Husserl's transcendental phenomenology: it is the role of embodiment and material agency that is so important in laboratories and industries. To a certain extent, Husserl himself was aware of this problem. This is why he dealt with embodiment in his Ideen II, and with what he called the lifeworld, the Lebenswelt, in his Crisis of the European Science. The lifeworld of history, of human work and instruments, includes the historically determined material agency to be found in laboratories. The phenomenological reduction to the lifeworld, after the world of theoretical idealizations has been suspended by the epoché, can be seen as an indispensible preliminary act before one performs the transcendental reduction that recollects us within the field of pure consciousness. A reduction to the lifeworld was tacitly performed by Bohr when he insisted that one should suspend any unified representation of the world, and take the formalism of quantum physics as just a "symbolic" anticipation of what can be found in the laboratory; and when he insisted that experimental apparatuses are to be described by using the ordinary language of our everyday life below the level of the quantum symbolism. But such a reduction to the lifeworld tends to be bypassed in the QBist approach to quantum mechanics. Indeed, the main difference between QBism and Bohr is the QBist's explicit refusal of any intermediate domain between the explored environment and the experience of observing and believing.

\section{Within the flesh, within the world}

By contrast, embodiment and human agency are natively taken into account by the phenomenological ontologies of Maurice Merleau-Ponty and Michel Henry. Let me start with Michel Henry, before I develop Merleau-Ponty's position at length.

According to Michel Henry (Henry 1985, Henry 2000, p. 72), any experience, including the experience of perceived objects, the experience of abstract forms, or the experience of one's own mental acts, ultimately turns out to be nothing else than an experience of the self-affection of one's own flesh. Pleasure and pain are taken as paradigmatic of self-affection, and even intentionality, even the assumption of transcendence of natural objects, must be (and is actually) rooted in the immanent impression that the flesh of a living being is making on itself. In other terms, even the perception of a patch of colour on some "outer" object is considered to be underpinned by a selfperception of the perceiver. One could say, as some contemporary neurobiologists do, that a perception is a guided dream of our flesh (a dream channelled by sensory inputs). Not even the most abstract conception of a 
mathematical structure can dispense with being rooted in some concrete selfsensitive modality of the living. Intentional consciousness is borne by nonintentional experience, and therefore the deepest layer of consciousness, the purest kind of experience, is nothing else than a naked self-sensitivity. Let me quote Michel Henry on this issue: "Original can only mean this: what comes in itself before any intentionality and independently of it, before the space of a gaze, before the 'outside oneself' of which intentionality is only a name; what comes ... before the world, out of the world, foreign to any conceivable "world', a-cosmic" (Henry 2000, p. 82). In other terms, according to Michel Henry, what comes before intentionality, and before the belief in a world, is the non-directional impression of being there: the awareness of being embodied, without any notion of the separation between one's own body and anything else; the silent voice of the body whose usual name is "cenesthesia". But once again, unlike the naturalistic program, which would try to account for the latter impression in terms of some interaction between natural objects (say the cells and organs) belonging to the human body, the phenomenological program adopts the diametrically opposite stance. It starts from the deepest layer of what we experience, and then tries to justify the belief in a natural world as a consequence of the multifarious differentiations and felt limitations of such a primeval experience.

This phenomenological program was developed and radicalized in Merleau-Ponty's last and posthumous book, The Visible and the Invisible. According to Merleau-Ponty, "we can accept a world ... only after having witnessed its arising from our experience of raw Being, which is like the umbilical cord of our knowledge, and our source of meaning" (Merleau-Ponty 1964, p. 209). As a consequence, instead of looking for an ontology of separate observable objects (as in the natural sciences) or an extension of such an ontology that encompasses conceivable atoms of experience (as in panpsychism), Merleau-Ponty's ontology is an ontology of immersion, of connivance, of acquaintance. Merleau-Ponty looks for an "oblique ontology" of intertwining (Saint-Aubert 2006), or, in his own terms, an "endo-ontology" (Merleau-Ponty 1964, p. 279). This is an ontology expressed from the inmost recesses of the process of being, rather than an ontology of the external contemplation of beings. This is an ontology of radical situatedness: an ontology in which we are not onlookers of a nature given out there, but rather intimately intermingled with nature, somewhere in the midst of it (MerleauPonty 1964, p. 152). Here, we cannot be construed as point-like spectators of what is manifest; instead, we are a field of experiences that merges with what appears in a certain region of it. This endo-ontology is therefore an ontology of the participant in Being, rather than an ontology of the observer of beings. In endo-ontology, Being is not presented before me as an object of sight, but my vision arises from the middle of Being. "Vision is the tool which allows me to be absent to myself, and to contemplate from within the fission of Being" (Merleau-Ponty 1985). This is a form of phenomenological embodied nondualism that was also expressed by Michel Henry (1963, p. 95): "Consciousness is identified with the process of self-tearing (...) of being". 
In Merleau-Ponty's philosophy, the archetypical element of our world that perfectly fits with an endo-ontology is our flesh. We perceive our flesh not as something separate, but as the perceiver that we are: a self-perceived perceiver. The flesh is that strange being endowed with complete reversibility, since it is jointly perceived and self-perceiving. The most obvious case of a two-faced kind of perception is the sense of touch, which, unlike distanced vision, is simultaneously appearance of what is touched and self-revelation of the touching in its carnal thickness. Here, two functions (toucher and touched) are realized by one and the same body. But this almost trivial remark was considered by Merleau-Ponty as paradigmatic of the true status of the whole world. "My" flesh is witness of the fundamentally fleshy nature of the world. "Where should we locate the boundary between the body and the world, Merleau-Ponty asks, since the world is flesh?" (Merleau-Ponty 1964, p. 182). In an endo-ontological framework, there are no such things as "me", "you", and the world, but a single canvas wherefrom various self-individualizing centers of sensitivity emerge, and which leaves patches of elementarity and half-obscurity between these centers (Barbaras 1993, p. 304). The role of constituting objectivity, which had been entrusted to the transcendental ego by Husserl, and which had been extended to our own-body by Merleau-Ponty at the time of his Phenomenology of Perception, was further extended to whatever has the status of a flesh by Merleau-Ponty at the time of The Visible and the Unvisible. But since the flesh is boundless, since the flesh is the whole world, any division between the constituter of objectivity and the constituted objects is meaningless. Just as the flesh is self-perceiving, the world qua flesh is self-objectifying.

\section{Endo-ontology and participatory realism}

Merleau-Ponty's "endo-ontology" strongly evokes the ontology that was elaborated by Chris Fuchs and other actors of the QBist adventure (despite the fact that their neglect of the intermediate level of bodies and instruments apparently brings them closer to Husserl's transcendental phenomenology than embodied phenomenology).

Fuchs' ontology was inspired by John Wheeler's post-Bohrian idea that quantum mechanics involves "observer-participancy". Just consider this sentence of Wheeler (2016): "The strange necessity of the quantum as we see it everywhere in the scheme of physics comes from the requirement that-via observer-participancy - the universe should have a way to come into being." Observer-participancy was thus ascribed a very strong meaning and a crucial role by Wheeler. For, according to him, any act of observer-participancy is capable of creating the universe, including its past! Some of the naivete of Wheeler "magical" retrospective creation of the universe by the observer's gaze is avoided by Chris Fuchs' participatory realism, but not all of it. Fuchs (2016) still uses the same word "creation" although in a more moderate form. He indeed accepts that each act of observer-participancy is a present act of creation. Yet he compares this act of creation with an act of reproduction of 
living beings, in which something new (a child!) arises out of the combination of previous elements (the genetic material of the parents). Instead of "creation", he could thus have used the more modest terms "emergence" or "co-generation".

The idea of participatory realism was born from Fuchs' wish to distance himself somehow from Asher Peres (who was his first teacher and collaborator). Fuchs wished to escape the accusation of "instrumentalism" and to develop his non-conventional version of realism instead. Yet, Asher Peres' endorsement of instrumentalism, and even positivism, is not necessarily to be understood as a philosophical rejection of participatory realism. It might well have been an overcautious statement of this very same doctrine. Consider the following key sentence in a joint paper of Peres and Fuchs (2000): "If the world is such that we can never identify a reality independent of our experimental activity, then we must be prepared for that, too".

From this sentence, one can adopt two strategies:

1) The first strategy, which was adopted by Fuchs, consists in building an overarching metaphysics. It is tantamount to seeking a metaphysical reason for the lack of success of ordinary metaphysics. It is tantamount to saying that the lack of independence of the symbols and statements of quantum theories with respect to our situation and experience reveals something crucial about the nature of reality: that it is highly entangled, thoroughly holistic, and that therefore our knowledge of it can only be participatory rather than representational.

2) The second strategy is anti-metaphysical. It is inspired by Wittgenstein's famous prescription according to which "What we cannot speak about we must pass over in silence". A defensor of this second strategy would express herself as follows. It is true that the characteristics of quantum mechanics irresistibly suggest that there is no such thing as a reality independent of us and our agency. But if this is so, the only thing we can do is renounce any representation or meta-representation, and devote our efforts to orienting ourselves and surviving in the putative participatory reality. We can hardly speak of what there is as if we were describing it from outside, for, in virtue of the very idea of a participatory reality, this would mean describing ourselvesinside as if we were outside! Then, according to this strategy, instrumentalism is just silent participatory realism.

A mischievous Wittgensteinian philosopher could insinuate that, conversely, participatory realism is noisy instrumentalism. But this might be an exaggeration. Participatory realism is truly useful, because it sketches the only conception of reality that is immediately compatible with quantum mechanics, and by doing so satisfies our want for mental pictures without indulging in wrong representations. Indeed, this mental picture is the only one that fully acknowledges the core reason of Bohr's prohibition of global ontological 
representations in quantum mechanics. It is a mental picture of the reason of the inadequacy of pictures. We could also say that participatory realism succeeds because it does not ascribe "reality" any positive predicate, but only a negative predicate: the impossibility of neatly splitting it into a spectator-like knower and a play-like known. This introduces us to what may be called "negative metaphysics", similar to the famous (or infamous) "negative theology". In the same way as "negative theology" may be taken by some as a good reason to abstain from theology, "negative metaphysics" may be taken by some (the instrumentalists) as a good reason to abstain from metaphysics.

\section{Merleau-Ponty's philosophy of quantum mechanics (1): beyond the classical paradigm}

Let's recapitulate this point. Merleau-Ponty's endo-ontology is an ontology for one who deeply participates in Being. And Chris Fuch's participatory realism is a non-external variety of realism for one who is deeply immersed in reality. This remarkable analogy is supported by Merleau-Ponty himself. Indeed, fifty years before QBism was formulated as a radicalization of the philosophical tendency that was initially adumbrated by Bohr, Merleau-Ponty acknowledged the strong kinship between the epistemological situation of quantum mechanics and his phenomenology of embodiment. He did so in two texts that remained unpublished until after his death: Visible and invisible, and the Lectures on Nature he delivered during the years 1959-1960 at the Collège de France.

Merleau-Ponty (1995, p. 117) started his reflection by noticing that, even in classical science where it seemed that the whole world could be treated as an object under a neutral and external gaze, there remained a huge blind spot. "Nature resists. It cannot be posited entirely before us. The body is a nature at work within us". The lived body, this double-faced natural reality, this felt locus of feelings, is averse to any conception of nature as a Big Object. Indeed, when we say that we "know" our own body, this is definitely not by taking it as an object of perception or thought, but by being acquainted with it, by coinciding with it, and by letting it self-reveal in our proprioceptive experience. Our own-body stubbornly resists objectification, and therefore the world of which it partakes resists universal objectification. Yet, classical science and even science to this day, did not completely renounce the project of universal objectification. As Merleau-Ponty pointed out, science tries to reabsorb its blind spot at any cost. "Science progressively reintroduces what it first excluded as subjective. But science wishes to reintroduce subjectivity as a special case of the relationships and objects that define the world according to it. Then, the world closes on itself, and except by what in us thinks and constructs science, we become parts of the big object" (Merleau-Ponty 1964, p. 31). Even the domain of psychology becomes objectified if classical physics is taken as an ideal. (Merleau-Ponty 1964, p. 36). In other terms, the reabsorption of its own blind spot by scientific research is an ongoing project that takes the form of an attempted naturalization of mind and consciousness. 
But this project implies (mis)taking mind and consciousness for parts of the "big natural object" called "the world".

However, a momentous episode of the history of science made this project obsolete even before its highly elusive completion. This episode is the advent of quantum mechanics. Indeed, quantum mechanics is simultaneously the most advanced stage of a long-term push towards objectivity, and the place where a fundamental limit of objectification manifests itself, though cryptically. Merleau-Ponty first notices that this manifestation of a fundamental limit of objectification is indeed so cryptic that "science has shown conservatism concerning the theory of knowledge" (Merleau-Ponty 1964, p. 33). Scientists tried to modify the contents of their knowledge without modifying their conception of knowledge, and to modify their view of an objective world while maintaining their objectivist naturalism. The reason why scientists have taken this conservative stance is that, without even knowing it, science is "rooted in pre-science"; it is rooted in the pre-science of common sense. However, as Merleau-Ponty explains, no one can truly understand quantum mechanics without accepting a deep transformation of our conception of knowledge. It is in vain that "some physicists frame in an objectivist ontology a physics that is no longer amenable to it" (Merleau-Ponty 1964, p. 45).

Now, the suitable transformation of our conception of knowledge is deep and devastating. It is one that challenges nothing less than the notions of common sense and the very duality of subject and object. Let me quote Merleau-Ponty once more: "Quantum physics does not put all truths on the side of the 'subjective', which would maintain the idea of an inaccessible objectivity. It rather challenges the very principle of this division and brings the contact between the observer and the observed in its very definition of "reality" (Merleau-Ponty 1964, p. 33). The new physics is then a strong incentive to recognize indirectly a truth that phenomenology knows directly: "that 'objective' and 'subjective' are domains hastily constructed out of a totalizing experience" (Merleau-Ponty 1964, p. 38).

On the basis of these remarks, Merleau-Ponty sketches the role of philosophy in our understanding of quantum mechanics. Philosophers, he says, can hardly take part in the technical debates about the formalism and its interpretation, let alone about experimental facts. But they become indispensible when "scientific being connects to pre-scientific being" (Merleau-Ponty 1995, p. 125). Their work becomes crucial when one is concerned with the way scientific knowledge is elaborated out of the pre-scientific layer of the lifeworld, and thereby overrides this pre-scientific layer without being independent of it.

However, when they pursue such an inquiry, philosophers are likely to make a disturbing discovery. By considering attentively the status of quantum mechanics, they discover that this physical theory only "helps us make negative philosophical discoveries"; they discover that "science does not 
impose an ontology ... It has only the power to remove false evidence from their alleged status of "evidence"” (Merleau-Ponty 1995, p. 139-145).

\section{Merleau-Ponty's philosophy of quantum mechanics (2): Probabilities}

This being said, Merleau-Ponty boldly entered into some details of the interpretation of quantum mechanics. He thus noticed that, in quantum physics, "(Probability) does not concern only our ignorance. With (quantum) indeterminism, we are dealing with pure probability ... Probability here enters into the texture of reality" (Merleau-Ponty 1995, p. 127). But this very statement that "probability enters into the texture of reality" is not to be understood as a claim in favor of "objective probabilities", similar to Popper's propensions or Heisenberg's potentialities. It must rather be understood by due consideration of the exceptional status of the wave function (or state vector) that allows one to calculate quantum probabilities. Notwithstanding their standard interpretation, wave functions are not a description of the state of an object. They rather describe the composite entity indissolubly made of a system, an apparatus and an observer (Merleau-Ponty 1995, p. 129). As a consequence, quantum probabilities do not reveal the ontological indeterminateness of the known objects out there; they rather express the indivisibility between the act of knowing and what is to be known.

And yet, measurements are still interpreted as if they were measurements of something, as if they were measurements that provide us with information about the properties of something. This tension between indivisibility and a project of division is what generates the measurement problem, but also what has the potential to dissolve it.

On the one hand, "The measurement operation, in wave mechanics, is an 'engaged' operation. Every operation of the new mechanics is an operation in the world, which is never foreign to the act of the one who makes the measurement" (Merleau-Ponty 1995, p. 131). The situation in quantum mechanics is thus reminiscent of our situation of embodiment, of the special status of our own body as a bifacial "flesh", and of the problem of knowing such an own-body: any operation of our own body is an operation within the "flesh of the world". We can then consider that the situation in quantum mechanics is an extension of the archetypal case of the own-body, with its twofold power of touching and being touched, that generated the concept of an endo-ontology. This extension is in perfect agreement with Merleau-Ponty's initial intuition. Indeed, according to him, the case of the flesh is paradigmatic of the true nature of the world, and the whole world should be treated as a big flesh rather than a big object. At the end of the day, quantum physics testifies that the world behaves as a big flesh, of which our flesh is a sample.

But on the other hand, "the role of the observer is to cut the chain of statistical probabilities, to bring out an existence in action. What makes this existence arise is not the intervention of a for-itself, but a thought that annexes a 
measurement apparatus". Only a thought can cut the chain of possibilities with probabilities and stop the chain at a point that is seen as an actuality; only a thought can cut the indivisible measurement chain, stop mentally the indivisible measurement dynamics, and interpret one aspect of this dynamics, one moment of the subject's experience, as a well-defined actual outcome. After all, something similar arises from many contemporary interpretations of quantum mechanics, such as Rovelli's "relational" interpretation: according to Rovelli, there is no fact of the matter about what is the "real" state of the system (a superposition or a sharp state) after a measurement has been performed. Here, what we still call the "state" is relative to a free option taken by the agent as to which epistemic situation she adopts (as a predictor or as an observer).

This being granted, Merleau-Ponty pointed out that "the problem posed by quantum physics is close to the problem of perception. Its duality is reminiscent of the duality of the perceptual process, in turn global and attentive" (Merleau-Ponty 1995, p. 135). In particular, the duality between the global expectations expressed by superposed state vectors, and the local actualities brought out by an interpreted measurement, is reminiscent of the Husserlian duality between global perceptive horizons and focused sensory fulfillment of some of the expectations adumbrated by such a horizon.

\section{Epilogue}

Merleau-Ponty concludes his philosophical analysis of quantum physics by siding with a very remarkable (but unfortunately almost forgotten) French philosopher of physics of the mid-twentieth century: Paulette Destouches Février. He quotes her approvingly when she declares: "We are dealing with a human physics, a physics of solidarity. Yet, physics cannot be interpreted in a purely idealistic way. It requires a form of realism that can be called "participatory"' (Merleau-Ponty, 1995, p. 135). Merleau-Ponty then recognizes explicitly that a good expression of his endo-ontology in quantum physics is the "participatory realism" advocated by Paulette Destouches-Février (1951).

It then turns out that participatory realism, this view entertained by several philosophers of physics, from Paulette Destouches-Février to Christopher Fuchs, who dismiss any attempt at interpreting quantum mechanics as a possible representation of the world, is a perfect match to Merleau-Ponty's endo-ontology of the world-flesh.

\section{Bibliography}

Aerts D. \& Sozzo S. (2014), "Entanglement zoo II : examples in physics and cognition", In: H. Atmanspacher, E. Haven, K. Kitto, D. Raine (eds.), Quantum Interaction 2013, Lecture Notes in Computer Science, vol 8369, Springer, 2014

Barbaras R. (1993), De l'être du phénomène, Jérôme Millon. 
Bell J.S. (1987), Speakable and Unspeakable in Quantum Mechanics, Cambridge: Cambridge University Press.

Bitbol M. (1996), Schrödinger's Philosophy of Quantum Mechanics, Dortrecht: Kluwer.

Bitbol M. (2009) (ed.), Théorie quantique et sciences humaines, Paris: CNRS Editions.

Brukner C. \& Zeilinger A. (2009), "Information Invariance and Quantum Probabilities", Foundations of Physics 39, 677-689.

Bruza P., Sofge D., Lawless W., van Rijsbergen C.J. \& Klusch M. (eds.) (2009a), Quantum interaction, Berlin: Springer.

Bruza P.D., Kitto K., Nelson D. \& McEvoy C., (2009b), "Is there something quantum-like about the human mental lexicon?", Journal of Mathematical Psychology, 53, 362-377.

Destouches-Février P. (1951), La structure des théories physiques, P.U.F.

Fuchs C.A. and A. Peres (2000) "Quantum theory needs no interpretation", Physics Today, 3, 70-71.

Fuchs C.A., N.D. Mermin, R. Schack (2014), "An Introduction to QBism with an Application to the Locality of Quantum Mechanics", American Journal of Physics, 82, 749-754.

Fuchs C. (2016), “On participatory realism”, ArXiv: 1601.04360v3 [quant$\mathrm{ph}$.

Grinbaum A. (2007), "Reconstructing instead of interpreting quantum theory", Philosophy of Science, 74, 761-774.

Healey R. (2017), The Quantum Revolution in Philosophy, Oxford University Press.

Henry M. (1963), L'essence de la manifestation, Presses Universitaires de France.

Henry M. (1985), Généalogie de la psychanalyse, Presses Universitaires de France.

Henry M. (2000), Incarnation, Éditions du Seuil.

Husserl E. (1960), Cartesian Meditations, The Hague: Martinus Nijhoff.

Husserl E. (1982), Ideas pertaining to a Pure Phenomenology, The Hague: Martinus Nijhoff. 
Husserl E. (2007), De la réduction phénoménologique, Jérôme Millon.

Kant I. ([1770] 2004), Inaugural Dissertation of 1770, Whitefish: Kessinger Publishing

Merleau-Ponty M. (1964), Le visible et l'invisible, Gallimard.

Merleau-Ponty M. (1985), L'œil et l'esprit, Gallimard.

Merleau-Ponty M. (1995), La nature, Notes. Cours du collège de France, Editions du Seuil.

Saint-Aubert E. de (2006), Vers une ontologie indirecte: sources et enjeux critiques de l'appel à l'ontologie chez Merleau-Ponty, Vrin.

Scheler M. (1993), Problèmes de sociologie de la connaissance, Paris: Presses Universitaires de France.

Schrödinger E. (1951), Science and Humanism, Cambridge: Cambridge University Press

Schrödinger E. (1954), Nature and the Greeks, Cambridge: Cambridge University Press.

Stengers I. (1997), Cosmopolitiques 4 : Mécanique quantique, la fin du rêve, Paris: La Découverte.

Thom R. (1993), Prédire n'est pas expliquer, Paris: Flammarion.

Tremblaye, de la, L. (2020) "QBism from a phenomenological point of view", in: H. Wiltsche \& P. Berghofer, (eds.), Phenomenological approaches to physics, Berlin: Springer

Tsirelson B., "Quantum analogues of the Bell inequalities. The case of two spatially separated domains", Journal of Soviet Mathematics, 36, 557-570, 1987

Wheeler J.A. (1978), "The 'Past' and the 'Delayed-Choice Double-Slit Experiment", in : A.R. Marlow (ed.) Mathematical Foundations of Quantum Theory, Academic Press.

Wheeler J.A. (2016), Interview, quoted by C. Fuchs, "On participatory realism”, ArXiv: 1601.04360v3 [quant-ph].

Wittgenstein L. ([1953] 1968), Philosophical Investigations, Oxford: Basil Blackwell.

Zwirn H. (2009), "Formalisme quantique et préférences indéterminées en théorie de la décision", in: M. Bitbol (ed.), Théorie quantique et sciences humaines, Paris: CNRS Editions. 
